\title{
Normoalbuminuric chronic kidney disease in type 1 diabetes: is it real and is it serious? Reply to Rigalleau V, Blanco $\mathrm{L}$, Alexandre $L$ et al [letter]
}

\author{
Giuseppe Penno $^{1} \cdot$ Eleonora Russo $^{1} \cdot$ Monia Garofolo $^{1} \cdot$ Giuseppe Daniele $^{1}$. \\ Daniela Lucchesi ${ }^{1}$ - Laura Giusti ${ }^{1}$ - Veronica Sancho Bornez ${ }^{1}$. Cristina Bianchi ${ }^{1}$. \\ Angela Dardano ${ }^{1} \cdot$ Roberto Miccoli $^{1} \cdot$ Stefano Del Prato $^{1}$
}

Received: 23 June 2017 / Accepted: 28 June 2017 /Published online: 2 August 2017

(C) Springer-Verlag GmbH Germany 2017

Keywords Albuminuria - Chronic kidney disease · CKD-EPI · Glomerular filtration rate · Type 1 diabetes mellitus

$\begin{array}{ll}\text { Abbreviations } \\ \mathrm{Alb}^{+} & \text {Albuminuric (CKD phenotype) } \\ \mathrm{Alb}^{-} & \text {Non-albuminuric (CKD phenotype) } \\ \mathrm{CKD} & \text { Chronic kidney disease } \\ \mathrm{CKD}- & \text { Chronic Kidney Disease Epidemiology } \\ \text { EPI } & \begin{array}{l}\text { Collaboration } \\ \text { EDIC }\end{array} \\ & \begin{array}{l}\text { Epidemiology of Diabetes Interventions and } \\ \text { Complications }\end{array} \\ \text { eGFR } & \text { Estimated GFR } \\ \text { MDRD } & \text { Modification of Diet in Renal Disease } \\ \text { mGFR } & \text { Measured GFR } \\ \text { RIACE } & \text { Renal Insufficiency And Cardiovascular Events }\end{array}$

To the Editor: We really appreciated the interest and comments by Rigalleau and colleagues on our recent article [1]. We agree that the proportion of individuals with the nonalbuminuric $\left(\mathrm{Alb}^{-}\right)$phenotype with type 1 diabetes and chronic kidney disease (CKD) in our study was surprisingly

Giuseppe Penno

pgiuse@immr.med.unipi.it

1 Diabetes and Metabolic Disease Section, Department of Clinical and Experimental Medicine, Azienda Ospedaliero-Universitaria Pisana, University of Pisa, 2 Via Paradisa, 56124 Pisa, Italy high (17 out of 29, 58.6\%) [2]. This figure is higher than that reported by Thorn et al [3] in the FinnDiane Study (78 out of 502, 15.5\%; $p<0.0001, \chi^{2}$ test) and, also, in the DCCT/Epidemiology of Diabetes Interventions and Complications (EDIC) Study [4], in which $23.6 \%$ of individuals ( 21 out of $89 ; p<0.001, \chi^{2}$ test) were reported as having normoalbuminuria (albumin excretion rate $[\mathrm{AER}] \leq 30 \mathrm{mg} /$

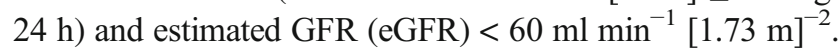
Nonetheless, our figure is similar to the one reported in the Renal Insufficiency And Cardiovascular Events (RIACE) Study [5], which enrolled a large cohort of Italian individuals with type 2 diabetes and found that 1673 out of 2959 (56.5\%) individuals with eGFR $<60 \mathrm{ml} \mathrm{min}{ }^{-1}[1.73 \mathrm{~m}]^{-2}$ had normoalbuminuria. The reasons for these discrepancies are not readily apparent. Whether local pathogenic background and clinical management could contribute to these differences is a hypothesis that needs to be verified.

Rigalleau et al claim that our results may be overestimated by the assessment of glomerular filtration rate by the Modification of Diet in Renal Disease (MDRD) Study equation. Though we are fully aware of the limitations of this equation, this is unlikely to account for the observed discrepancies as the same approach was used in the DCCT/EDIC survey [4]. Moreover, as reported in the supplementary material of our study (ESM Table 5 [2]), individuals with CKD and the $\mathrm{Alb}^{-}$phenotype had higher MDRD equation-eGFR vs those with the albuminuric $\left(\mathrm{Alb}^{+}\right)$phenotype $(52 \pm 7 \mathrm{vs}$ $\left.45 \pm 11 \mathrm{ml} \mathrm{min}^{-1}[1.73 \mathrm{~m}]^{-2} ; p<0.05\right)$. This difference was probably even larger in the FinnDiane [3] study, in which participants with $\mathrm{CKD}$ and the $\mathrm{Alb}^{-}$phenotype had a median (interquartile range) eGFR, calculated by the Chronic Kidney Disease Epidemiology Collaboration (CKD-EPI) formula [6], of 55 (49-58), whilst those with the $\mathrm{Alb}^{+}$phenotype had an eGFR of $37(23-51) \mathrm{ml} \mathrm{min}^{-1}[1.73 \mathrm{~m}]^{-2}$. Furthermore, a less 
advanced renal failure has been consistently reported in those with $\mathrm{CKD}$ and the $\mathrm{Alb}^{-}$phenotype compared with the $\mathrm{Alb}^{+}$ phenotype in the RIACE Study [5].

It is well known that the MDRD equation can underestimate GFR, as compared with measured GFR (mGFR), particularly in the normal to high range [7]. The CKD-EPI equation also appears to underestimate normal to high GFR to a similar extent as the MDRD equation in people with diabetes [8]. Whether MDRD equation-eGFR underestimation also occurs in individuals with stage $3 \mathrm{CKD}$ is a matter of debate [9]. MacIsaac et al [8] suggest that the precision of GFR estimates by the MDRD and CKD-EPI equations improves with lower GFR values; in their study, in 60 participants with mGFR

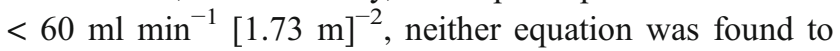
significantly underestimate GFR. This is in full agreement with data reported by Rigalleau et al showing that MDRD equation-eGFR was similar to GFR measured by ${ }^{51} \mathrm{Cr}$ EDTA in 40 individuals with type 1 diabetes, even in those with stage $3 \mathrm{a}$ CKD. In 288 individuals with diabetes (125 with type 1 diabetes), we have previously shown that MDRD equation-eGFR underestimates GFR measured by iohexol plasma clearance to a progressively larger extent in those with mGFR $>75 \mathrm{ml} \mathrm{min}^{-1}[1.73 \mathrm{~m}]^{-2}$, but not in individuals with mGFR $45-<60 \mathrm{ml} \mathrm{min}^{-1}[1.73 \mathrm{~m}]^{-2}$ [10]. In our hands [10], the difference between MDRD equation-eGFR and MGFR was $-1.8 \%$ in individuals with stage $3 \mathrm{a}$ CKD and $+2.8 \%$ in individuals with mGFR $60-75 \mathrm{ml} \mathrm{min}^{-1}[1.73 \mathrm{~m}]^{-2}$.

Moreover, estimation of GFR by the CKD-EPI equation instead of the MDRD equation did not change the conclusions and the overall results presented in our paper [2]. In more detail, CKD-EPI equation-derived eGFR was $55.6 \pm 8.1 \mathrm{ml} \mathrm{min}^{-1}$ $[1.73 \mathrm{~m}]^{-2}$ and $48.2 \pm 11.9 \mathrm{ml} \mathrm{min}^{-1}[1.73 \mathrm{~m}]^{-2}$ in those with $\mathrm{CKD}$ and the $\mathrm{Alb}^{-}$and $\mathrm{Alb}^{+}$phenotype, respectively $(p=0.056)$; only two out of the 17 individuals with the $\mathrm{Alb}^{-}$ phenotype and stage $\geq 3 \mathrm{CKD}$ were reclassified as having stage 2 CKD because of a CKD-EPI formula-measured eGFR $>60 \mathrm{ml} \mathrm{min}{ }^{-1}[1.73 \mathrm{~m}]^{-2}\left(63.3\right.$ and $63.9 \mathrm{ml} \mathrm{min}^{-1}$ $\left.[1.73 \mathrm{~m}]^{-2}\right)$. Finally, out of 63 individuals with the $\mathrm{Alb}^{-}$ phenotype and eight individuals with the $\mathrm{Alb}^{+}$phenotype, all with MDRD equation-eGFR $60-74 \mathrm{ml} \mathrm{m^{-1 }}[1.73 \mathrm{~m}]^{-2}, 16$ and 2 were reclassified as having a higher eGFR using the CKD-EPI equation, respectively. However, even taking this into account did not affect results and conclusions of our analysis.

We agree with Rigalleau et al that relatively higher eGFR in individuals with the $\mathrm{Alb}^{-}$phenotype and stage $\geq 3 \mathrm{CKD}$ may reflect a slower rate of deterioration of renal function with reduced progression to end-stage renal disease (ESRD). Since we did not measure this outcome, data from our study cannot prove or disprove this theory. However, the hypothesis is supported by data reported by Rigalleu et al in a 3 year follow-up of their study [11] and by the FinnDiane's longer 13 year follow-up [3]. In the second Joslin Kidney Study, the prevalence of 'decliners' (those with renal decline $\geq 3.3 \%$ per year) was $10 \%$ in individuals with the $\mathrm{Alb}^{-}$phenotype, vs $32 \%$ with the $\mathrm{Alb}^{+}$ phenotype [12]. Of interest, the prevalence of decliners increased ( $\mathrm{Alb}^{-}$to $21 \%$ and $\mathrm{Alb}^{+}$to $48 \%$ ) among those with eGFR $<60 \mathrm{ml} \mathrm{min}^{-1}[1.73 \mathrm{~m}]^{-2}$, suggesting that individuals with $\mathrm{CKD}$ and the $\mathrm{Alb}^{-}$phenotype can progress to advanced kidney disease.

The final question raised by Rigalleau and colleagues is also of importance: whether individuals with albuminuria are more prone to cardiovascular events and mortality. We have already speculated whether the distinct sets of factors associated with the $\mathrm{Alb}^{-}$and $\mathrm{Alb}^{+}$phenotype could confer a differential cardiovascular risk. This is actually supported by the results of the FinnDiane [3], which show an increased cardiovasular risk, even in individuals with the $\mathrm{Alb}^{-}$phenotype with CKD (HR 2.0 [95\% CI 1.4, 3.5]) vs individuals with the $\mathrm{Alb}^{-}$without $\mathrm{CKD}$ (reference cohort). As far as our cohort is concerned, the distribution of individuals with CKD and a positive history of previous cardiovascular events did not differ between the $\mathrm{Alb}^{-}$group (7 out of 17, 41.2\%) and the $\mathrm{Alb}^{+}$ group ( 3 out of 12, 25.0\%; $p=0.449$ ).

In summary, given the many limitations of estimating vs measuring GFR, we believe our data are consistent with a growing literature showing a progressive increase of the prevalence of the non-albuminuric CKD phenotype. Since equations are commonly used in the clinical setting, it is important for physicians to appreciate the existence of such a phenotype and its implications in stratifying renal and cardiovascular risk.

Acknowledgements We are indebted to the Clinical Laboratory and the Medical Records Unit of the Department of Clinical and Experimental Medicine (both at the University of Pisa, Pisa, Italy).

Funding Work in the authors' laboratories is supported by a grant from Regione Toscana, Italy, Resolution 1157 (19 December 2011), ID number D55E11002680005. The funding body had no role in study design, data collection and analysis, decision to publish or preparation of the manuscript.

Duality of interest The authors declare that there is no duality of interest associated with this manuscript.

Contribution statement All authors were responsible for drafting the article and revising it critically for important intellectual content. All the authors approved the version to be published.

\section{References}

1. Rigalleau V, Blanco L, Alexandre L et al (2017) Normoalbuminuric chronic kidney disease in type 1 diabetes: is it real and is it serious? Diabetologia. doi:10.1007/s00125-017-4378-0

2. Penno G, Russo E, Garofolo M et al (2017) Evidence for two distinct phenotypes of chronic kidney disease in individuals with type 1 diabetes mellitus. Diabetologia 60:1102-1113 
3. Thorn LM, Gordin D, Harjutsalo V et al (2015) The presence and consequence of nonalbuminuric chronic kidney disease in patients with type 1 diabetes. Diabetes Care 38:2128-2133

4. Molitch ME, Steffes M, Sun W et al (2010) Development and progression of renal insufficiency with and without albuminuria in adults with type 1 diabetes in the Diabetes Control and Complications Trial and the Epidemiology of Diabetes Interventions and Complications Study. Diabetes Care 33:1536-1543

5. Penno G, Solini A, Bonora E et al (2011) Clinical significance of nonalbuminuric renal impairment in type 2 diabetes. J Hypertens 29:1802-1809

6. Levey AS, Stevens LA, Schmid CH et al (2009) CKD-EPI (chronic kidney disease epidemiology collaboration). A new equation to estimate glomerular filtration rate. Ann Intern Med 150:604-612

7. Stevens LA, Coresh J, Feldman HI et al (2007) Evaluation of the modification of diet in renal disease study equation in a large diverse population. J Am Soc Nephrol 18:2749-2757
8. MacIsaac RJ, Ekinci EI, Premaratne E et al (2015) The Chronic Kidney Disease-Epidemiology Collaboration (CKD-EPI) equation does not improve the underestimation of glomerular filtration rate (GFR) in people with diabetes and preserved renal function. BMC Nephrol 16:198

9. Froissart M, Rossert J, Jacquot C, Paillard M, Houillier P (2005) Predictive performance of the modification of diet in renal disease and Cockcroft-Gault equations for estimating renal function. J Am Soc Nephrol 16:763-773

10. Pucci L, Triscornia S, Lucchesi D et al (2007) Cystatin C and estimates of renal function: searching for a better measure of kidney function in diabetic patients. Clin Chem 53:480-488

11. Rigalleau V, Lasseur C, Raffaitin C et al (2007) Normoalbuminuric renal-insufficient diabetic patients: a lower-risk group. Diabetes Care 30:2034-2039

12. Krolewski AS (2015) Progressive renal decline: the new paradigm of diabetic nephropathy in type 1 diabetes. Diabetes Care 38:954-962 